\title{
Yozgat ili Memeli Faunası (Classis: Mammalia)
}

\author{
Tarkan YORULMAZ ${ }^{*}$, Nurhan ARSLAN ${ }^{2}$ \\ ${ }^{1}$ Çankırı Karatekin Üniversitesi, Yaprakll Meslek Yüksek Okulu, Ormancılık Bölümü, Avcılık ve Yaban Hayatı \\ Programi, Ballıca Yerleşkesi, Çankırı \\ ${ }^{2}$ Çankırı Karatekin Üniversitesi, Fen Bilimleri Enstitüsü, Rektörlük Ek Hizmet Binası, Yeni Mahalle, Çankırı \\ (ORCID:0000-0002-9033-7162)(ORCID: 0000-0002-4928-4767)
}

\begin{abstract}
$\ddot{O} \mathbf{z}$
Bir alandaki memeli tür zenginliği o bölgenin ekosistem zenginliği yanında ekolojik dengesinin de bir yansımasıdır. Yozgat ili zengin bir ekosistem çeşitliliğine sahip olup, hem İç Anadolu hem de Karadeniz bölgesinin özelliklerini göstermektedir. Bu çalıma 2016-2018 yılları arasında Yozgat ili memeli türlerini tespit etmek amacıyla gerçekleştirilmiştir. Çalışma sonucunda Yozgat ilinden Eulipotyphla, Chiroptera, Lagomorpha, Rodentia, Carnivora ve Cetartiodactyla takımlarına mensup 41 memeli türünün varlığı saptanmıştır. Bu çalışma ile Yozgat ilinden Mehelyi'nin nalburunlu yarasası Rhinolophus mehelyii, çentikli yarasa Myotis emerginatus, Savi'nin cüce yarasası (Hypsugo savii) ve vaşak (Lynx lynx)'in ilk kez kaydı verilmiştir. Kontrolsüz avcılık, tarım zararlılarıyla zirai mücadele, karayollarında meydana gelen araç çarpmaları ve su kaynaklarının tahribinin memeli türlerini olumsuz etkileyen önemli faktörler olduğu gözlenmiştir. Yozgat ilinde tespit edilen memeli türleri içinde su kaynakları için indikatör bir tür olan Lutra lutra, orman ekosistemlerinin hedef türü olarak kabul edilen kızıl geyik (Cervus elaphus), karaca (Capreolus capreolus), bozayı (Ursus arctos) ve vaşak (Lynx lynx)' in yayllış gösterdiği alanlar öncelikli korunması gereken alanlar olarak dikkate alınmalıdır.
\end{abstract}

Anahtar kelimeler: Memeliler, yayılış, Yozgat, Turkiye.

\section{Mammals Fauna of Yozgat Province (Classis: Mammalia)}

\begin{abstract}
The mammal species richness in a field is a reflection of the ecosystem richness of that region as well as its ecological balance. Yozgat province has a rich ecosystem diversity and shows both the characteristics of both Central Anatolia and the Black Sea region. This study was carried out between 2016-2018 to identify the mammal species of Yozgat province. As a result of the study, 41 mammal species belonging to Eulipotyphla, Chiroptera, Lagomorpha, Rodentia, Carnivora and Cetartiodactyla teams from Yozgat province were determined. With this study, Mehelyi's horseshoe bat Rhinolophus mehelyii, notch-eared bat Myotis emerginatus, Savi's pipistrelle bat Hypsugo savii and lynx Lynx lynx were recorded for the first time fromYozgat province. It has been observed that uncontrolled hunting, pest control against agricultural pests, vehicle crashes on roads and the destruction of water resources are important factors that negatively affect mammalian species.Among the mammal species identified in Yozgat province, otter Lutra lutra, which is an indicator for water resources, the areas where red deer Cervus elaphus, roe deer Capreolus capreolus, bear Ursus arctos and lynx Lynx lynx, which are accepted as the target species of forest ecosystems, should be considered as priority areas to be protected.
\end{abstract}

Keywords: Mammals, distribution Yozgat, Turkiye.

\section{Giriş}

Memeli sınıfinın dünyada 29 takım, 153 familya, 1229 cinse ait 5416 türü bulunurken [1], Türkiye'de 8 takıma mensup 161 tür ile temsil edilmektedir. [1-4]. Yapılan literatür çalışması sonucunda Yozgat ilinden 4 takıma ait 19 türün kaydedildiği tespit edilmiştir [5-27]. Ancak Demirsoy [2] ve IUCN [28]'in

"Sorumlu yazar: tarkan.yorulmaz@gmail.com

Geliş Tarihi: 24.01.2020, Kabul Tarihi: 10.02.2020 
yayılış haritaları göz önüne alındı̆̆ında Yozgat ilinde Eulipotyphla, Chiroptera, Carnivora, Lagomorpha, Rodentia ve Cetartiodactyla takımlarına mensup 50 türün yayılışı verilmiştir. Yozgat ili memeli türleri ile ilgili az sayıda çalışma bulunmaktadır. Bu çalışmalar bazı türler üzerine odaklanmış olup, özellikle küçük memeli türleri üzerine çalışmalar yapılmıştır [10,13,21,27].

Yozgat ilinin yüz ölçümü $14.097 \mathrm{~km}^{2}$ olup, denizden yüksekliği 1300 m'dir. Yozgat ili İç Anadolu bölgesinde yer almasına rağmen coğrafi özellikleri bakımından kuzey ilçeleri Karadeniz Bölgesi'nin özelliğini taşımaktadır. Su kaynakları bakımından Türkiye'nin iki büyük akarsuyu olan Kızılırmak ve Yeşilırmak havzaları Yozgat ilini de kapsamaktadır. Bu durum Yozgat ilinde önemli sulak alan habitatlarını oluşturmaktadır [29].

Yozgat ilinde bugüne kadar memeli türlerinin tespitine yönelik kapsamlı bir çalışma yapılmamıştır. Yozgat ili, ilçe ve doğal çevrelerinde yaşayan memeli türlerini tespit etmek ve memeli türleri açısından önemli alanları belirlemek bu çalışmanın amacını oluşturmaktadır.

\section{Materyal ve Metot}

Yozgat ili sınırları içerisinde yayılış gösteren memeli türlerinin tespiti için 2016-2018 tarihleri arasında $10 \mathrm{~km} \mathrm{X} 10 \mathrm{~km}$ büyüklüğünde yaklaşı 110 paftada (285 lokalite) toplam 55 günlük arazi çalısmas1 yapılmıştır (Şekil 1). Arazi çalışması yapılan noktaların yükseklikleri $660 \mathrm{~m}$ ve $1890 \mathrm{~m}$ arasında değişmiştir. Arazi çalışmaları 1/25.000'lik paftaların en az \% 10'luk kısmında ve paftada bulunan orman, yüksek dağ, bozkır, sulak alan, kumul, tarım ve yerleşim gibi başlıca habitat tiplerini temsil edecek biçimde yapılmıştır.

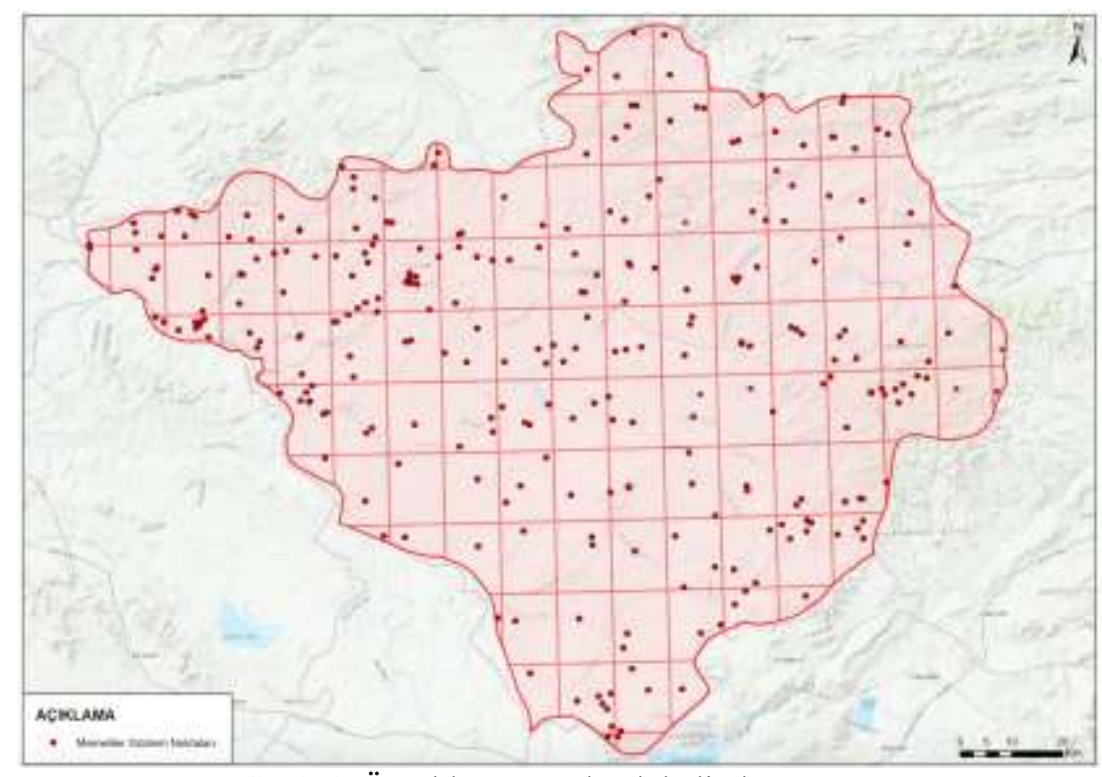

Şekil 1. Örnekleme yapılan lokaliteler

Arazi çalışmaları her mevsim en az bir kez olacak şekilde Yozgat ili ilçe ve doğal çevrelerinde gerçekleştirilmiştir. Büyük memeli türlerini temsil eden örnekler fotokapan, dürbün, kamera ve fotoğraf makinesi ile tespit edilmiştir. Arazi gözlemleri sırasında doğrudan memelilerin görülmesi esasına dayalı gözlemlerin yanı sıra memelilere ait ayak izi, dışkı, kı1, boynuz, yeme-ısırma, taş çevirme, araç çarpması sonucu ölmüş bireyler, kırıp-dökme gibi iz, belirti ve işaretlerden gibi dolaylı gözlemlerden de yararlanılmıştır. Büyük memelilerin izlerine rastlandığı yerlere, uygun habitatlara, duyumların alındığ1 yerlere fotokapan yerleştirilerek büyük memeli türleri tespit edilmiştir. Küçük memeli türlerinden böcekçil ve kemirgenler için uygun habitatlara canlı yakalama kapanları kurularak örnekler yakalanıp tür tespitleri yapılmıştır. Hayvanlar için kapan kurulan alanlar ve yakalanan türler fotoğraflanmıştır. Ayrıca bu alanların habitat bilgileri ve koordinatları kaydedilmiştir. Yarasa türleri için ise eski ve terk edilmiş binalar, in ve mağaralar ve kaya yarıkları gibi alanlarda gözlemler yapılmıştır. Misnet, atrap, el feneri ve yarasa dedektörü kullanılarak bölgede bulunan yarasa türleri tespit edilmiştir. 


\section{Bulgular}

Yozgat ilinde 2016-2018 yılları arasında yapılan bu çalışma ile toplam 41 memeli türü tespit edilmiştir. Bu türlerin 28'i küçük memeli ve 13'ü ise büyük memelidir (Tablo 1). Yozgat ilinin kuzey kesimlerinde bulunan meşelik alanlarda karaca (Capreolus capreolus), Akdağmadeni-Çayıralan arasında bulunan yoğun ormanlık alanda ise kızıl geyik (Cervus elaphus), boz ayı (Ursus arctos), kurt (Canis lupus) ve vaşak (Lynx lynx) gibi önemli türler kaydedilmiştir. Bununla birlikte Yozgat ili iç su ekosistemlerinde tespit edilen su samuru ( Lutra lutra) bölgedeki akarsu ve dere gibi sulak alanların sağlıklı olduğunu göstermesi açısından önemli bir kayıt olmuştur. Bu çalışma ile Yozgat ilinden Mehelyi’nin nalburunlu yarasası Rhinolophus mehelyii, çentikli yarasa Myotis emerginatus, Savi'nin cüce yarasası (Hypsugo savii) ve vaşak (Lynx lynx)'ın ilk kez kaydı verilmiştir.

\section{Tartışma ve Sonuç}

Literatür verilerine göre Yozgat ilinde 50 memeli türünün kaydı bulunmaktadır. Bu kayıtların 32'i Demirsoy [2] ve IUCN [28] verilerine göre dağılım haritalarında örneksiz ve tahmini olarak Yozgat iline dâhil edilmiştir. Yozgat ilinden bugüne kadar örneğe dayalı 19 tür kaydı verilmiştir [5-27]. Bu çalışma ile 25 memeli türünün Yozgat ilinden tespiti yapılmıştır. Bununla birlikte Yozgat ilinde yayılış gösteren memeli tür sayısı 44'e yükselmiştir. Tespit edilen 25 türden Rhinolophus mehelyii, Hypsugo savii, Myotis emerginatus ve Lynx lynx Yozgat ili için yeni kayıt olma özelliği taşımaktadır.

Yozgat İli sınırları içerisinde herhangi bir endemik memeli türü bulunmamaktadır. Yozgat ilindeki nesli tehlike altındaki türlerin belirlenmesinde, türlerin Türkiye'deki ve dünya genelindeki yayılışları ile popülasyon durumları veya IUCN değerlendirmeleri dikkate alınmıştır.

Yozgat ilinde gerçekleştirilen memeli türlerinin tespit çalışmasında Boğazlıyan, Saraykent, Şefaatli, Çekerek ve Merkez ilçelerinde bulunan mağaralarda 8 farklı yarasa türü (Rhinolophus ferrumequinum, $R$. hipposideros, R. mehelyii, Myotis blythi, M. myotis, M.emerginatus, Pipistrellus pipistrellus, Miniopterus schreibersii) doğrudan gözlenmiştir. Merkezde yer alan Yozgat Çamlı̆̆ Milli Parkı'nda yarasa detektörü ile yapılan taramalarda ise Hypsugo savii türünün varlığı tespit edilmiştir. Böylece Yozgat ilinden toplam 9 yarasa türü bu çalışma ile kaydedilmiştir. Bu yarasa türlerinden $R$. mehelyii, M. emerginatus ve H. savii Yozgat'tan ilk kez kaydedilmişleridir (Şekil 2, Şekil 3). R. mehelyii IUCN kriterlerine göre "VU" (Vulnerable / Hassas) kategorisinde hassas bir türdür. Bu nedenle Yozgat ilinde tespit edildiği mağaralar korunmalı ve izlemeye alınmalıdır.

Yozgat ilinde ağırlıklı olarak yer alan step ve tarım alanlarına yakın yerlerde nadiren orman alanlarında ve riparian alanlarda yapılan gözlemlerde 16 kemirici türü tespit edilmiştir. Bu türlerden ağırlıklı dağılımı Anadolu'da İran-Turan fitocoğrafik bölgesinde yer alan Spermophilus xanthoprymnus IUCN kriterlerine göre "NT" (Near Threatened / Tehtide yakın) olarak değerlendirilmekte olup, Yozgat ilinde önemli bir popülasyonu bulunmaktadır. Bu popülasyon Orta Anadolu'da kuzey ormanlarına doğru Çayıralan ilçe sınırlarında tespit edilmiştir. Ayrıca tarım alanlarının genişletilmesi bu türün habitatlarına zarar vermekte olup, türün yayılışını ve alandaki varlığını tehdit etmektedir. Yozgat ili Çayıralan ilçesindeki orman içi açıklıklarında tespit edilen popülasyon izlenmeli ve Spermophilus xanthoprymnus'un İç Anadolu steplerindeki popülasyonları ile genetik açıdan ilişkisi ortaya konmalıdır.

Yozgat ilinde farklı habitatlarda ekosistemin en üst basamağında yer alan etçiller takımına ait 9 tür tespit edilmiştir. Bu türler içerisinde bulunduğu habitatı en iyi temsil eden türlerden biri su samuru (Lutra lutra)'dur (Şekil 4). Su samuru tatlı su ekosistemlerinde özellikle Yozgat ili Şefaatli ilçesi ile Yerköy ilçesi arasında akan Delice ırmağı üzerindeki varlığı bu su kaynağının besin değeri taşıdığını ve ekolojik olarak hala bir değer taşıdığını göstermektedir. Su samuru IUCN kriterlerine gore "NT" (Near Threatened / Tehtide yakın) olarak değerlendirlmekte ve riparian bitki örtüsüne zarar veren projeler (dere, ırmak, nehir vb. akarsularla ilgili baraj, kanal, kanalet, drenaj, kum ocakları vb), anız yangınları ve su debisindeki değişiklikler ile besin değerlerinin değişmesi sonucu tür doğrudan tehdit edilmektedir. 


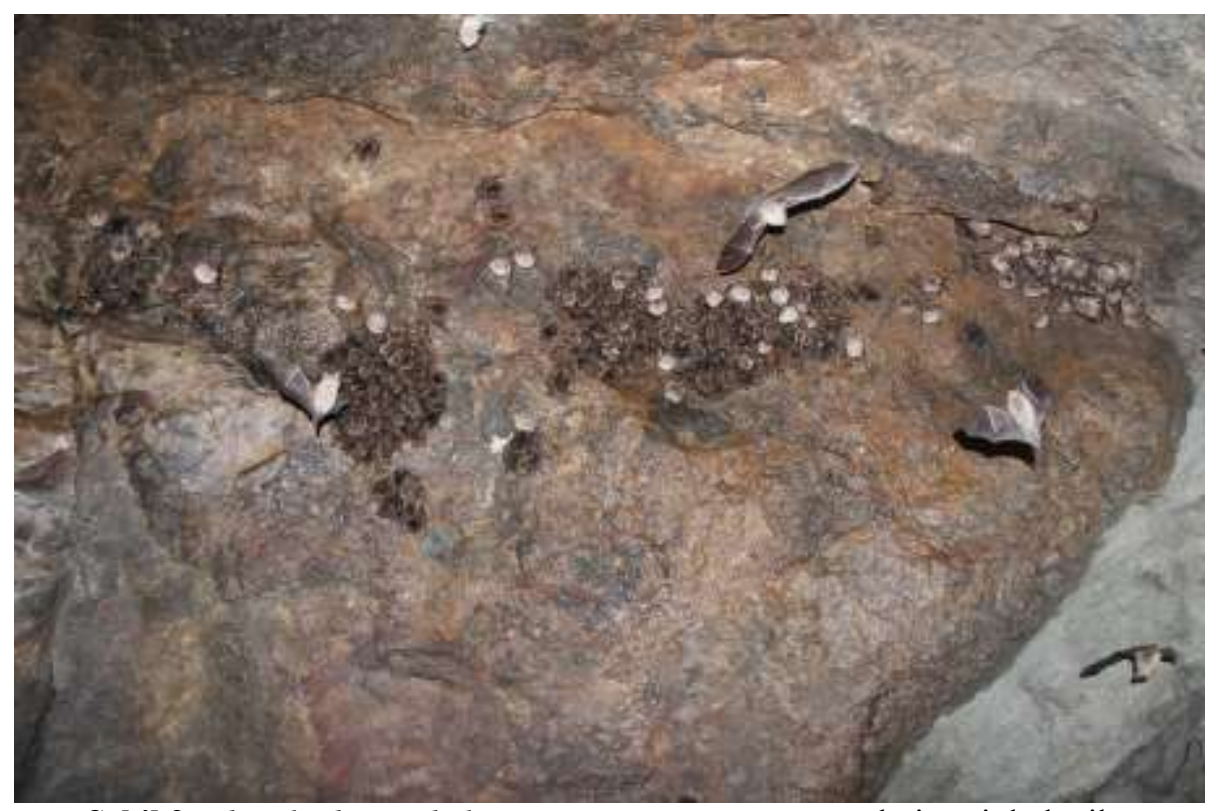

Şekil 2. Rhinolophus mehelyii ve Myotis emerginatus türlerine ait koloniler

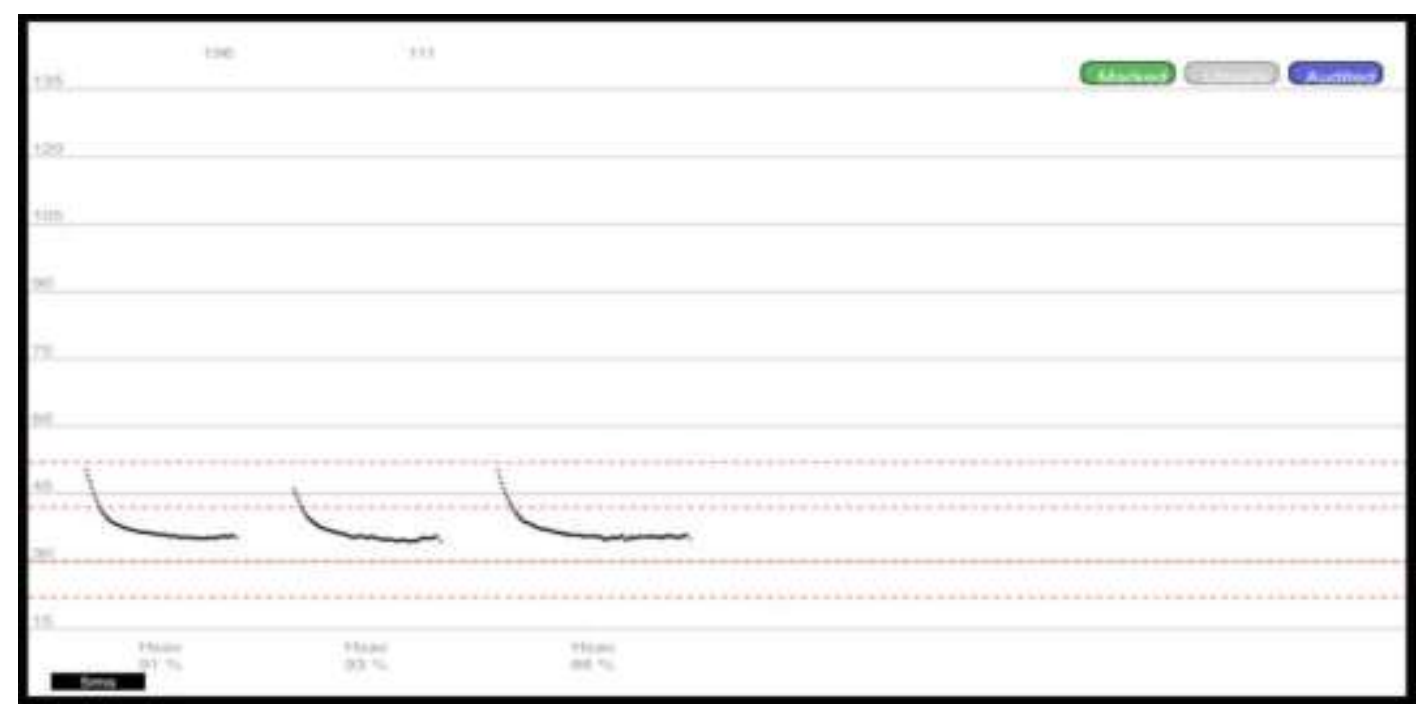

Şekil 3. Yozgat Çamlığı Milli Parkı'nda tespit edilen Hypsugo savii’ye ait ses kaydı sonogramı

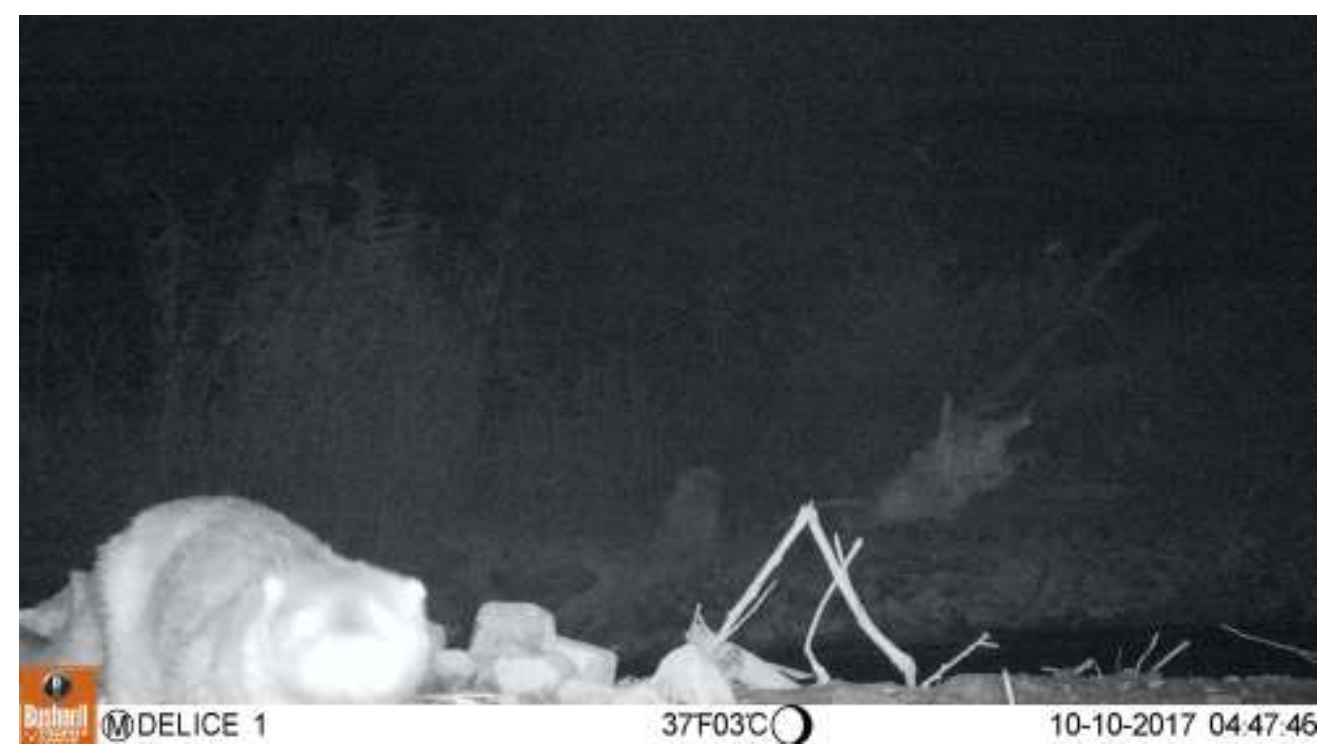

Şekil 4. Yozgat Aşağıelmahacılı köyünde tespit edilen Lutra lutra'ya ait fotokapan görüntüsü 
Yozgat ilinde tespit edilen önemli yırtıcı türlerinden biri de nadir görünen Alaca sansar (Vormela peregusna)'dır (Şekil 5). Bu tür IUCN kriterlerine gore "VU" (Vulnerable/Hassas) olarak değerlendirilmekte ve Yozgat ilinde tarım alanlarının yakınlarında yuvalanmaktadır. Bununla birlikte Akdağmadeni-Çayıralan arası sık orman ekosisteminde sağlıklı bir popülasyona sahip boz ayı (Ursus arctos) ve vaşak (Lynx lynx) bu bölgede gerçekleştirilen fotokapan çalışmalarında tespit edilmişlerdir (Şekil 6, Şekil 7).

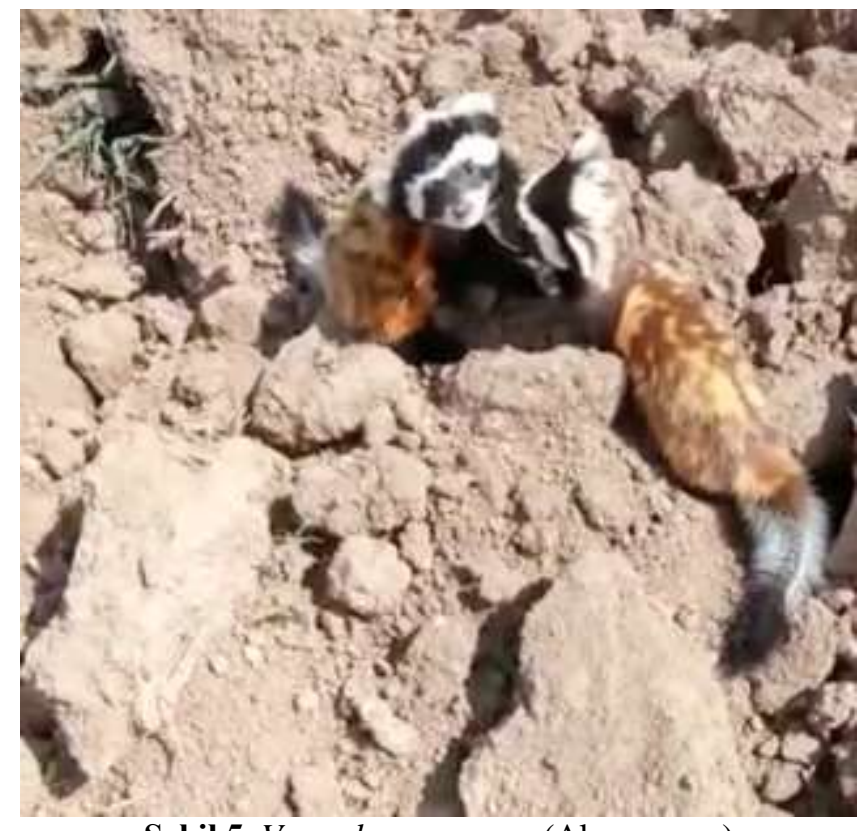

Şekil 5. Vormela peregusna (Alacasansar)

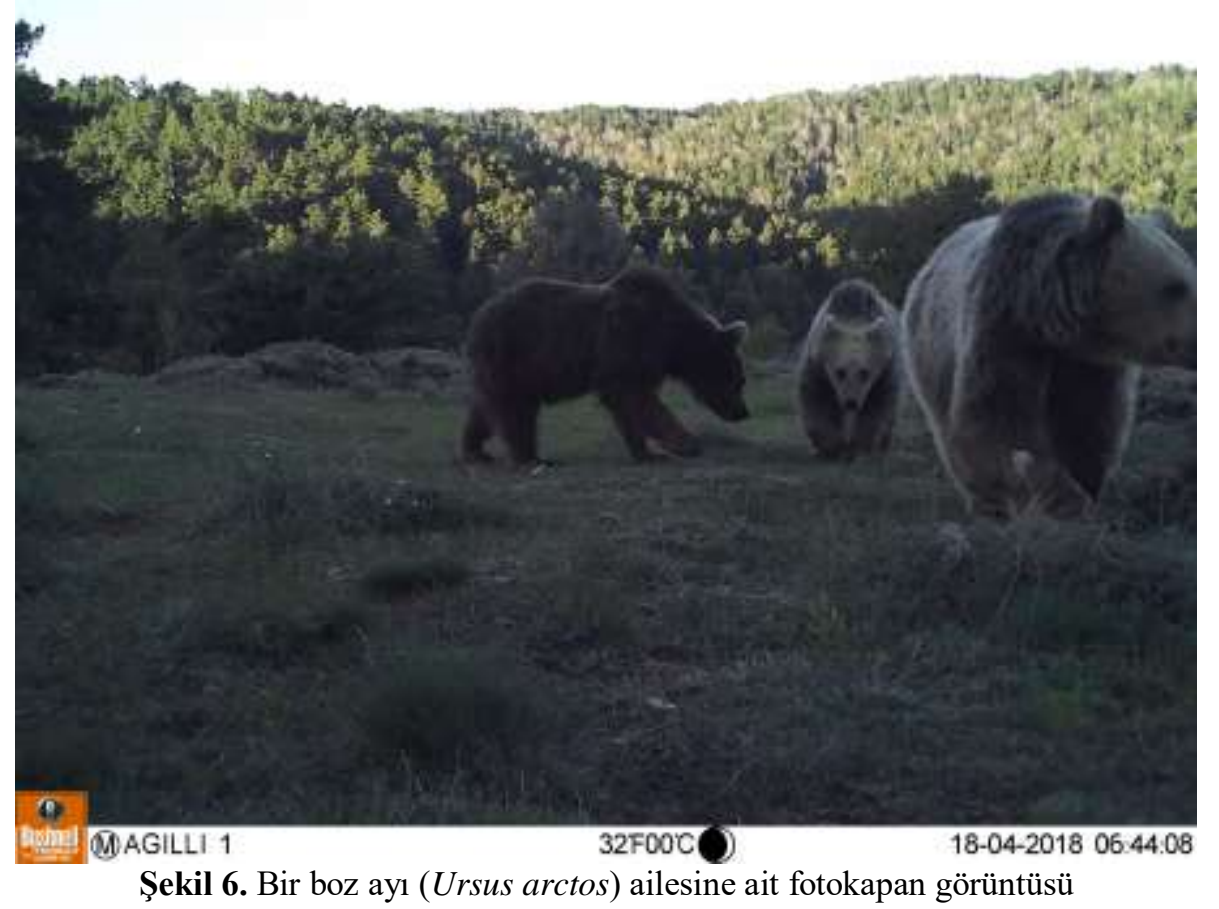




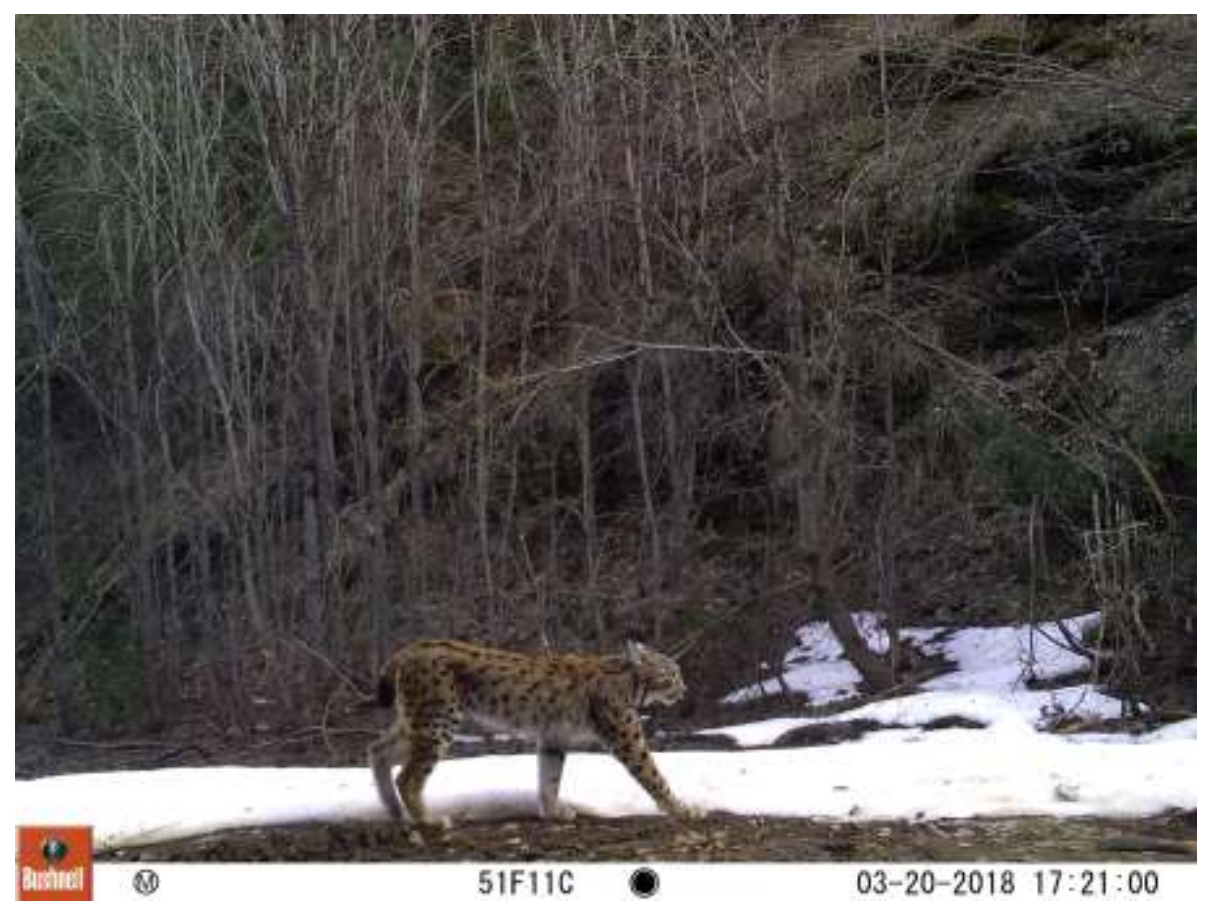

Şekil 7. Çayıralan ilçesi ormanlık alanında tespit edilen vaşak (Lynx lynx)'a ait fotokapan görüntüsü

Kızıl geyik (Cervus elaphus)'in gösterge tür olarak seçilmesinin nedeni açık ve ormanlık alanların birleştiği kısımlarda besin ihtiyacını gidermektedir. Dinlenebileciği sık ağaçlardan oluşan ormanlara ihtiyaç duymaktadır. Bu alanların yangın, kesim vb. şekillerde ortadan kalkması halinde türün popülasyonunun zayıflaması alanda habitat kaybı yaşandığının bir göstergesi olabilir. IUCN kriterlerine gore "LC" (Least Concern / En Az Endişe Verici) olarak değerlendirilen kızıl geyik (Cervus elaphus) orman içerisindeki sık ağaçların oluşturduğu alanlarda beslenme ve üreme faaliyetlerini gerçekleştirmektedirler. Bu alanların yangın, kesim vb. şekillerde ortadan kalkması halinde türün popülasyonunun zayıflamasına neslinin devamlılığına tehdit oluşmasına sebep olmaktadır. Yaşam alanı olarak geniş yapraklı ve karışık ormanları tercih etmelerine rağmen iğne yapraklı çalılıklarda ve geniş açıklıklara sahip ormanlarda da yayılış gösterirler. Gecenin alacakaranlığında aktif olup gündüzleri ormanın sessiz sakin yerlerinde dinlenmeye çekilirler. Orman içindeki kesimlerde ya da insan tahribatının olduğu yerlerde yaşam alanlarının daralmasına söz konusu olabilir.

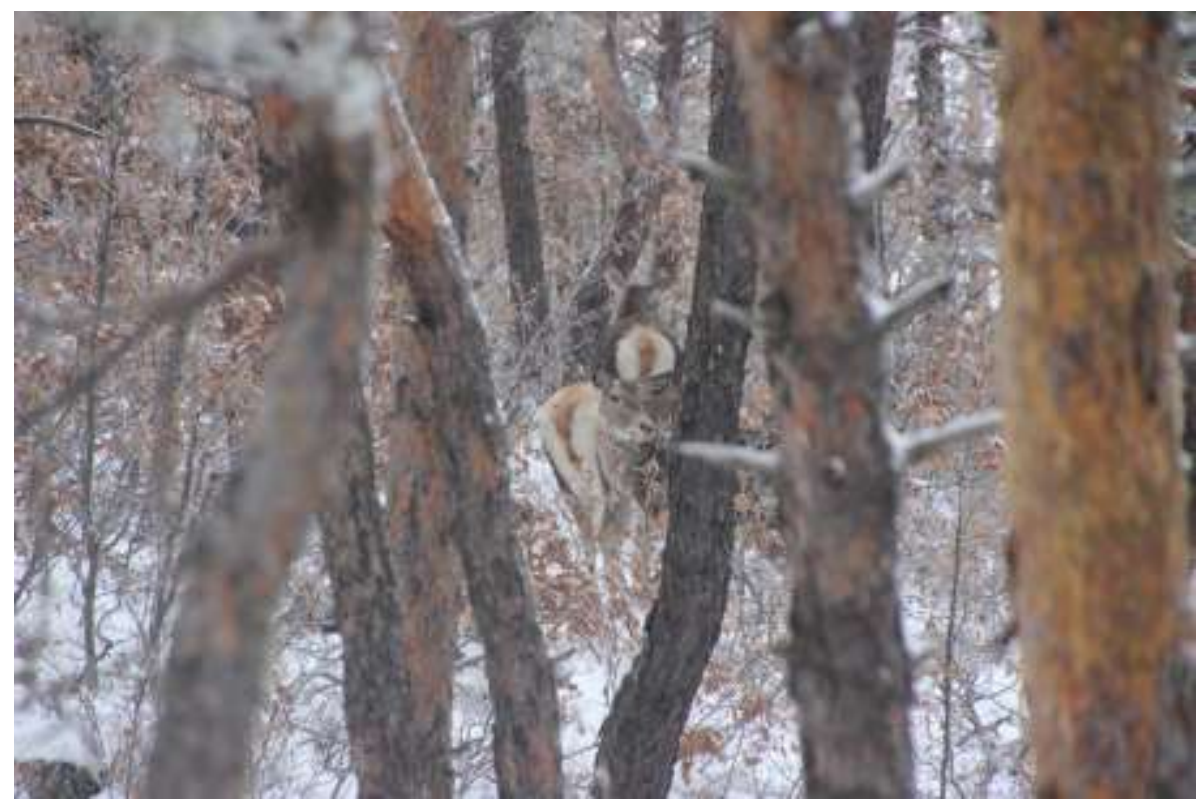

Şekil 8. Oluközü Tabiat Parkı'nda tespit edilen kızıl geyik (Cervus elaphus)'e ait fotokapan görüntüsü 
Yozgat ilinde tespit edilen memeliler arasında av hayvanı olarak değerlendirilen ve bu bakımdan ekonomik öneme sahip tek tür Yaban domuzu (Sus scrofa)'dur.

Yozgat ilinde yayılış gösteren türlerden 21'i Bern Sözleşmesi Ek-II ve 12'si ise Bern Sözleşmesi Ek-III listesinde yer almaktadır. 23 tür ise Bern Sözleşmesine göre liste dışıdır. Memeli türleri arasında IUCN Red List Kategorileri Listesi'ne göre 2 tür "VU" (Vulnerable / Hassas), 4 tür de "NT" (Near Threatened/Neredeyse Tehdit Altında), 49 tür "LC" (Least Concern / En Az Endişe Verici) ve 1 tür de "DD" (Data Deficient / Yetersiz Veri) kategorisinde yer almaktadır. Ayrıca 3 tür CITES Ek-I ve 1 tür de CITES Ek-III listelerinde yer almaktadır.

Arazi çalışmaları sonucu Yozgat ilinde yaşayan memeli türlerinin habitatlarında oluşan yada oluşabilecek tehditler incelenmiştir. Arazi çalışmalarında incelenen bölgelerde kaçak avcılık, habitat tahribi, yarasaların bulunduğu mağara ve kovuklara insanların kontrolsüz girişleri, araç çarpma vakaları ve tarım alanlarında kullanılan zirai ilaçlamalar olumsuz etkiler olarak tespit edilmiştir. Arazi çalışmaları sırasında bölgede av yapıldığıyla ilgili tüfeklerden arda kalan fişekler, vurulmuş ve ormanlık alanlara bırakılmış memeli yaban hayvanları kaydedilmiştir. Bu durumdan dolayı koruma faaliyetlerinin arttırılması ve yerel halkın bilinçlendirilerek hayvanların ekolojik dengedeki önemleri konusunda bilgilendirilmeleri için toplantılar düzenlenmesi gerekmektedir. Tarım alanlarında kullanılması muhtemel mücadele yöntemlerinden zehir kullanımının türe özgü olarak uygulanması ve zehirlenip ölen hayvanlardan diğer hayvanların etkilenmemesi için dikkat edilmelidir.

Tablo 1. Yozgat ilinde 2016-2018 yılları arasında yapılan bu çalışma ve Literatür bulgularına göre tespit edilen memeli türleri ve korunma durumları.

\begin{tabular}{|c|c|c|c|c|c|c|c|}
\hline Tür & Türkçe Adı & IUCN & MAKK & BERN & CITES & Bu çalışma & Literatür \\
\hline $\begin{array}{l}\text { Erinaceus } \\
\text { concolor }\end{array}$ & Kirpi & $\mathrm{LC}$ & & & & Bu çalışma & $1,2,28,31,32$ \\
\hline $\begin{array}{l}\text { Crocidura } \\
\text { suaveolens }\end{array}$ & Sivri burunlu fare & $\mathrm{LC}$ & & EK-III & & Bu çalışma & $1,2,11,12,25,27,28,31,32$ \\
\hline $\begin{array}{l}\text { Crocidura } \\
\text { leucodon }\end{array}$ & $\begin{array}{l}\text { Sivri burunlu tarla } \\
\text { faresi }\end{array}$ & $\mathrm{LC}$ & & EK-III & & & $1,2,11,12,28,31,32$ \\
\hline $\begin{array}{l}\text { Rhinolophus } \\
\text { ferrumequinum }\end{array}$ & $\begin{array}{l}\text { Büyük nal burunlu } \\
\text { yarasa }\end{array}$ & $\mathrm{LC}$ & & EK-II & & Bu çalışma & $1,2,16,28,31$ \\
\hline $\begin{array}{l}\text { Rhinolophus } \\
\text { hipposideros }\end{array}$ & $\begin{array}{l}\text { Küecük nal burunlu } \\
\text { yarasa }\end{array}$ & $\mathrm{LC}$ & & EK-II & & Bu çalışma & $1,2,28,31$ \\
\hline $\begin{array}{l}\text { Rhinolophus } \\
\text { mehelyii }\end{array}$ & $\begin{array}{l}\text { Nal burunlu } \\
\text { yarasa }\end{array}$ & VU & & EK-II & & Bu çalışma & \\
\hline Myotis myotis & $\begin{array}{l}\text { Büyük farekulaklı } \\
\text { yarasa }\end{array}$ & $\mathrm{LC}$ & & EK-II & & Bu çalışma & $1,2,16,20,28,31$ \\
\hline Myotis brandtii & Sakallı yarasa & $\mathrm{LC}$ & & EK-II & & & $1,2,16,28,31$ \\
\hline $\begin{array}{l}\text { Myotis } \\
\text { emerginatus }\end{array}$ & Çentikli yarasa & $\mathrm{LC}$ & & EK-II & & Bu çalışma & \\
\hline $\begin{array}{l}\text { Myotis } \\
\text { mystacinus }\end{array}$ & $\begin{array}{l}\text { Küçük sakallı } \\
\text { yarasa }\end{array}$ & $\mathrm{LC}$ & & EK-II & & & $1,2,28,31$ \\
\hline $\begin{array}{l}\text { Myotis } \\
\text { aurascens }\end{array}$ & $\begin{array}{l}\text { Bozkır bıyıkl1 } \\
\text { yarasası }\end{array}$ & $\mathrm{LC}$ & & EK-II & & & $1,2,28,31$ \\
\hline Myotis blythii & $\begin{array}{l}\text { Küçük farekulaklı } \\
\text { yarasa }\end{array}$ & $\mathrm{LC}$ & & EK-II & & $\mathrm{Bu}$ çalışma & $1,2,8,16,20,28,31$ \\
\hline $\begin{array}{l}\text { Eptesicus } \\
\text { serotinus }\end{array}$ & $\begin{array}{l}\text { Geniş kanatlı } \\
\text { yarasa }\end{array}$ & $\mathrm{LC}$ & & EK-II & & & $1,2,5,6,7,9,14,28,31$ \\
\hline $\begin{array}{l}\text { Pipistrellus } \\
\text { pipistrellus }\end{array}$ & Cüce yarasa & LC & & EK-III & & Bu çalışma & $1,2,28,31$ \\
\hline Hypsugo savii & $\begin{array}{l}\text { Savinin cüce } \\
\text { yarasası }\end{array}$ & $\mathrm{LC}$ & & EK-II & & Bu çalışma & \\
\hline $\begin{array}{l}\text { Plecotus } \\
\text { kolombatovici }\end{array}$ & & $\mathrm{LC}$ & & EK-II & & & $1,2,28,31$ \\
\hline $\begin{array}{l}\text { Plecotus } \\
\text { macrobullaris }\end{array}$ & $\begin{array}{l}\text { Dağ uzun kulaklı } \\
\text { yarasası }\end{array}$ & LC & & EK-II & & & $1,2,28,31$ \\
\hline $\begin{array}{l}\text { Miniopterus } \\
\text { schreibersii }\end{array}$ & $\begin{array}{l}\text { Uzun kanatlı } \\
\text { yarasa }\end{array}$ & NT & & EK-II & & Bu çalışma & $1,2,28,31$ \\
\hline Tadarida teniotis & Kuyruklu yarasa & $\mathrm{LC}$ & & EK-II & & & $1,2,28,31$ \\
\hline Lepus europaeus & Tavşan & $\mathrm{LC}$ & EK-II & EK-III & & Bu çalışma & $1,2,23,28,31$ \\
\hline
\end{tabular}




\begin{tabular}{|c|c|c|c|c|c|c|c|}
\hline Tür & Türkçe Adı & IUCN & МАКК & BERN & CITES & Bu çalışma & Literatür \\
\hline $\begin{array}{l}\text { Spermophilus } \\
\text { xanthoprymnus }\end{array}$ & $\begin{array}{l}\text { Gelengi, tarla } \\
\text { sincab1 }\end{array}$ & NT & & & & $\mathrm{Bu}$ çalışma & $1,2,3,18,28,31,33,35$ \\
\hline $\begin{array}{l}\text { Allactaga } \\
\text { williamsi }\end{array}$ & Arap tavşanı & $\mathrm{LC}$ & & & & Bu çalışma & $1,2,3,28,31,33$ \\
\hline $\begin{array}{l}\text { Arvicola } \\
\text { amphibius }\end{array}$ & Su sıçanı & $\mathrm{LC}$ & & & & Bu çalışma & $1,2,3,28,31,34$ \\
\hline $\begin{array}{l}\text { Microtus } \\
\text { hartingi }\end{array}$ & Tarla faresi & $\mathrm{LC}$ & & & & Bu çalışma & $1,2,3,25,27,28,31,34$ \\
\hline Microtus socialis & Sosyal tarla faresi & $\mathrm{LC}$ & & & & & $1,2,3,28,31,34$ \\
\hline Microtus levis & $\begin{array}{l}\text { Uzun kuyruklu } \\
\text { çayır tarlafaresi }\end{array}$ & $\mathrm{LC}$ & & & & Bu çalışma & $1,2,3,2527,28,31,34$ \\
\hline $\begin{array}{l}\text { Microtus } \\
\text { dogramacii }\end{array}$ & $\begin{array}{l}\text { Doğramacı tarla } \\
\text { faresi }\end{array}$ & $\mathrm{LC}$ & & & & & $1,2,3,28,31,34$ \\
\hline $\begin{array}{l}\text { Cricetulus } \\
\text { migratorius }\end{array}$ & Cüce avurtlak & LC & & & & Bu çalışma & $1,2,3,22,2527,28,31,34$ \\
\hline $\begin{array}{l}\text { Mesocricetus } \\
\text { brandti }\end{array}$ & Avurtlak & NT & & & & Bu çalışma & $1,2,3,25,27,28,30,31,34$ \\
\hline $\begin{array}{l}\text { Meriones } \\
\text { tristrami }\end{array}$ & Türkiye Çöl sıçanı & $\mathrm{LC}$ & & & & Bu çalışma & $1,2,3,25,27,28,31$ \\
\hline $\begin{array}{l}\text { Apodemus } \\
\text { mystacinus }\end{array}$ & $\begin{array}{l}\text { Büyük dişli orman } \\
\text { faresi }\end{array}$ & $\mathrm{LC}$ & & & & Bu çalışma & $1,2,3,17,25,28,31,34$ \\
\hline $\begin{array}{l}\text { Apodemus } \\
\text { witherbyi }\end{array}$ & $\begin{array}{l}\text { Çizgili orman } \\
\text { faresi }\end{array}$ & $\mathrm{LC}$ & & & & Bu çalışma & $1,2,3,17,25,27,28,31,34$ \\
\hline $\begin{array}{l}\text { Mus } \\
\text { macedonicus }\end{array}$ & Ev faresi & $\mathrm{LC}$ & & & & $\mathrm{Bu}$ çalışma & $1,2,3,25,27,28,31,34$ \\
\hline Mus musculus & Ev faresi & $\mathrm{LC}$ & & & & Bu çalışma & $1,2,3,28,31,34$ \\
\hline Rattus rattus & Ev sıçanı & $\mathrm{LC}$ & & & & Bu çalışma & $1,2,3,28,31,34$ \\
\hline $\begin{array}{l}\text { Rattus } \\
\text { norvegicus }\end{array}$ & Göçmen fare & $\mathrm{LC}$ & & & & & $1,2,3,28,31,34$ \\
\hline $\begin{array}{l}\text { Nannospalax } \\
\text { xanthodon }\end{array}$ & Kör fare & DD & & & & Bu çalışma & $1,2,3,10,13,21,28,31,34$ \\
\hline $\begin{array}{l}\text { Dryomys } \\
\text { nitedula }\end{array}$ & Ağaç yedi uyuru & $\mathrm{LC}$ & & EK-III & & Bu çalışma & $1,2,3,28,31,33$ \\
\hline Canis lupus & Kurt & $\mathrm{LC}$ & & EK-II & EK-I & Bu çalışma & $1,2,26,28,31$ \\
\hline Canis aureus & Çakal & $\mathrm{LC}$ & EK-II & & EK-III & Bu çalışma & $1,2,28,31$ \\
\hline Vulpes vulpes & Tilki & $\mathrm{LC}$ & EK-II & & & Bu çalışma & $1,2,19,26,28,31$ \\
\hline Mustela nivalis & Gelincik & $\mathrm{LC}$ & EK-I & EK-III & & Bu çalışma & $1,2,28,31$ \\
\hline $\begin{array}{l}\text { Vormela } \\
\text { peregusna }\end{array}$ & Alacasansar & VU & & EK-II & & Bu çalışma & $1,2,24,28,31$ \\
\hline $\begin{array}{l}\text { Meles } \\
\text { meles }\end{array}$ & Porsuk & LC & EK-I & EK-III & & Bu çalışma & $1,2,28,31$ \\
\hline $\begin{array}{l}\text { Martes } \\
\text { foina }\end{array}$ & Kaya sansarı & $\mathrm{LC}$ & EK-II & EK-III & & Bu çalışma & $1,2,28,31$ \\
\hline $\begin{array}{l}\text { Martes } \\
\text { martes }\end{array}$ & Ağaç sansarı & LC & & EK-III & & & $1,2,28,31$ \\
\hline $\begin{array}{l}\text { Lutra } \\
\text { lutra }\end{array}$ & Su samuru & NT & & EK-II & EK-I & Bu çalışma & $1,2,28,31$ \\
\hline $\begin{array}{l}\text { Ursus } \\
\text { arctos }\end{array}$ & Boz ayı & $\mathrm{LC}$ & & EK-II & EK-I & Bu çalışma & $1,2,28,31$ \\
\hline $\begin{array}{l}\text { Felis } \\
\text { silvestris }\end{array}$ & Yabani kedi & $\mathrm{LC}$ & & EK-II & & & $1,2,28,31$ \\
\hline $\begin{array}{l}\text { Sus } \\
\text { scrofa }\end{array}$ & Yaban domuzu & $\mathrm{LC}$ & EK-II & & & Bu çalışma & $1,2,28,31$ \\
\hline $\begin{array}{l}\text { Capreolus } \\
\text { capreolus }\end{array}$ & Karaca & $\mathrm{LC}$ & & EK-III & & Bu çalışma & $1,2,28,31$ \\
\hline $\begin{array}{l}\text { Sciurus } \\
\text { anomalus }\end{array}$ & Anadolu sincab1 & $\mathrm{LC}$ & & EK-II & & Bu çalışma & \\
\hline $\begin{array}{l}\operatorname{Lyn} x \\
\operatorname{lynx}\end{array}$ & Vaşak & $\mathrm{LC}$ & & EK-III & & Bu çalışma & \\
\hline $\begin{array}{l}\text { Cervus } \\
\text { elaphus }\end{array}$ & Kızıl geyik & LC & & EK-III & & Bu çalışma & \\
\hline
\end{tabular}




\begin{tabular}{|l|l|c|c|c|c|c|c|}
\hline Tür & Türkçe Adı & IUCN & MAKK & BERN & CITES & Bu çalışma & Literatür \\
\hline Suncus etruscus & Etrüsk sivri faresi & LC & & EK-III & & & 25,27 \\
\hline $\begin{array}{l}\text { Apodemus } \\
\text { sylvaticus }\end{array}$ & $\begin{array}{l}\text { Bayağı orman } \\
\text { faresi }\end{array}$ & LC & & & & & 25,27 \\
\hline
\end{tabular}

\section{Teşekkür}

Bu çalışma Tarım ve Orman Bakanlığı, Doğa Koruma ve Milli Parklar Genel Müdürlüğü, 9. Bölge Müdürlüğü, Yozgat İl Müdürlügünün destekleri ile gerçekleştirilmiştir. Doğa Koruma ve Milli Parklar Yozgat İl Müdürlüğ̈̈'nün bütün ekibine saha çalışmalarındaki desteklerinden dolayı teşekkür ediyoruz. Ayrıca Ekonorm Çevre İş Sağlığı ve Güvenliği Ölçüm Hiz. Müh. San. Tic. Ltd. Şti. şirketine çalışma boyunca göstermiş oldukları katkılarından dolayı teşekkür ediyoruz.

\section{Yazarların Katkısı}

Başlıca yazar saha çalışmalarında ve makalenin yazımında ağırlıklı katkıya sahiptir. İkinci yazar saha çalışmalarının \%10'luk kısmında yer almış ve makale yazımının ise \%20'lik kısmına katkı sunmuştur.

\section{Çıkar Çatışması Beyanı}

Yazarlar arasında herhangi bir çıkar çatışması bulunmamaktadır.

\section{Araştırma ve Yayın Etiği Beyanı}

Yapılan çalışmada, araştırma ve yayın etiğine uyulmuştur. Araştırma etik kurul izni gerektirmemektedir.

\section{Kaynaklar}

[1] Wilson E.D., Reeder M.D., (Eds.) 2005. Mammal Species of the World: A Taxonomic and Geographic. 2nd ed., Smiths. Inst. Press. Washington, D.C., 1-1207.

[2] Demirsoy A. 1996. Türkiye Omurgalıları-Memeliler. Çevre Bakanlığı, Meteksan, Ankara, 1-292.

[3] Yiğit, N., Çolak, E., Sözen, M., Karataş, A., 2006. Rodents of Türkiye (Türkiye Kemiricileri). Meteksan, Ankara, 1-154.

[4] Biyolojik Çeşitlilik İzleme Raporu, 2012.

[5] Danford C.G., Alston E.R. 1877. On the mammals of Asia Minor Part I. Proc. Zool. Soc. Lond. 1877: 270-282.

[6] Dobson G.E. 1878. Catalogue of the Chiroptera in the Collection of the British Museum. London: British Museum (Natural History), 567 pp.

[7] Çağlar M. 1965. Chiropteran fauna der Türkci. İstanbul Üniv. Fen Fak. Mec., Seri B 30: 125-134.

[8] Albayrak İ. 1993. The bats of Western Turkey and their distribution (Mammalia: Chiroptera) Doğa-Turk. J. Zool., 17:237-257.

[9] Spitzenberger F. 1994. The Genus Eptesicus (Mammalia, Chiroptera) in southern anatolia. Folia Zool., 43: 437-454.

[10] Yüksel E., Gülkaç M.D. 1995. Kızılırmak Havzası Kayseri Kırşehir Nevşehir Yozgat kesimi Spalax popülasyonları üzerine sitogenetik incelemeler. TBAG-904, 1-22.

[11] Kefelioğlu H., Tez C. 1999. he Distribution Problem of Crocidura russula (Hermann, 1780) (Mammalia: Insectivora) in Turkey. Tr. J. of Zoology, 23: 247-251.

[12] Tez C. 2000. Taxonomy and Distribution of the White-Toothed Shrews (Crocidura) (Soricidae: Insectivora: Mammalia) of Turkey. Turk J Zool 24: 365-374.

[13] Yüksel E., Gülkaç M.D. 2001. The cytogenetical comparasions of Spalax (Rodentia: Spalacidae) populations from middle Kizılırmak Basin, Turkey. Turk. J. Biol., 25: 17-24.

[14] Aşan N., 2001. Karyotype of Eptesicus serotinus (Schreber, 1774) in Turkey. (Mammalia: Chiroptera). Turk. J. Zool., 25: 357-360.

[15] Benda P., Karataş A. 2005. On some Mediterranean populations of bats of the Myotis mystacinus morpho-group (Chiroptera: Vespertilionidae). Lynx (Praha), n. s., 36: 9-38. 
[16] Karataş A., Sözen M. 2006. Bats of the middle and upper Kız1lırmak regions, Central Anatolia, Turkey (Chiroptera). Lynx (Praha), n. s., 37: 151-159.

[17] Çolak R., Çolak E., Yiğit N., Kandemir İ., Sözen M. 2007. Morphometric and Biochemical Variation and the Distribution of the Genus Apodemus (Mammalia: Rodentia) in Turkey. Acta Zoologica Academiae Scientiarum Hungaricae 53 (3): 239-256.

[18] Gündüz İ., Jaarola M., Tez C., Yeniyurt C., Polly P.D., Searle J.B. 2007. Multigenic and morphometric differentiation of ground squirrels (Spermophilus, Sciuridae, Rodentia) in Turkey, with description of a new species. Molecular Phylogenetics and Evolution, 43: 916-935.

[19] İbiş O. 2009. Türkiye Kızıl Tilkilerinin (Vulpes vulpes (L.,1758)) (Mammalia: Carnivora) Mitokondrial Sitokrom -B Sekansı Yardımıyla Genetik Analizi. Doktora Tezi, Erciyes Üniversitesi, Fen Bilimleri Enstitüsü, Kayseri.

[20] Aşan N., Albayrak İ., Yorulmaz T. 2010.Noteworthy records of Myotis myotis and Myotis blythii in Turkey (Chiroptera: Vespertilionidae). Lynx, n. s. (Praha), 41: 145-150.

[21] Yağcı T. 2010. İç Anadolu Bölgesi Nannospalax leucodon (Nordmann, 1840)'un G Bantlama Ve Allozim Varyasyonları (Mammalia: Rodentia). Doktora Tezi, Kırıkkale Üniversitesi Fen Bilimleri Enstitüsü, Kırıkkale.

[22] İbiş O., Tez Ç., Özcan S., Kılıç M., Telcioğlu M. 2011. A Preliminary Study of the Allozyme Variation in the Grey Hamster, Cricetulus migratorius (Mammalia: Rodentia), from the Asian Part of Turkey. Arch. Biol. Sci., Belgrade, 63 (2): 381-391.

[23] Demirbaş Y., Albayrak İ. 2013. Türkiye Yaban Tavşanının Bugünkü Durumu. Türk Bilimsel Derlemeler Dergisi, 1: 192-194.

[24] İbiş O., Tez C. 2014. Phylogenetic Status and Genetic Diversity of the Turkish Marbled Polecat, Vormela peregusna, (Mustelidae: Carnivora: Mammalia), inferred from the Mitochondrial Cytochrome bGene. Vertebrate Zoology, 64 (2): 285 - 294.

[25] Arslan N., Candan A., Yorulmaz T. 2015. Fatih Tabiat Parkı (Yozgat) Uzun Kulaklı Orman Baykuşu (Asio otus)'nun Diyetindeki Memeli Kompozisyonu. XII. Ulusal Ekoloji ve Çevre Kongresi14-17 Eylül 2015 Muğla

[26] Aksöyek E., İbiş O., Özcan S., Moradi M., Tez C. 2016. DNA barcoding of three species (Canis aureus, Canis lupus and Vulpes vulpes) of Canidae. Mitochondrial DNA Part A. 28 (5): 745-755

[27] Yorulmaz T., Arslan N. 2019. Investigation on Diet of Long-Eared Owl (Asio Otus) Inhabiting Fatih Natural Park (Turkey). Bitlis Eren Üniversitesi Fen Bilimleri Dergisi, 8 (3): 865-859.

[28] IUCN (International Union for Conservation of Nature) 2008. Sepcies. The IUCN Red List of Threatened Species. Version 2015-3.

[29] Yozgat İl Çevre durum Raporu, 2011, Yozgat Valiliği, Çevre ve Şehircilik İl Müdürlügü.

[30] Aşan N. 2012. Nucleolar organizer regions in Mesocricetus brandti (Nehring, 1898) (Mammalia: Rodentia) from the Yozgat and Tokat provinces of Turkey. Turk J Zool., 36 (2): 255-257.

[31] Demirsoy A. 1992. Yaşamın Temel Kuralları, Omurgalılar / Amniyota (Sürüngenler, Kuşlar ve Memeliler). Cilt-III / Kısım- II., Meteksan A.Ş. Ankara, 1-942.

[32] Kryštufek B., Vohralík V. 2001. Mammals of Turkey and Cyprus. Introduction, Checklist, Insectivora. Koper: Science and Research Centre of the Republic of Slovenia, $140 \mathrm{pp}$.

[33] Kryštufek B., Vohralik V. 2005. Mammals of Turkey and Cyprus, Rodentia I: Sciuridae, Dipodidae, Gliridae, Arvicolinae. Zalozba Annales, Koper, Slovenia, 1-292.

[34] Kryštufek B., Vohralík V. 2009. Mammals of Turkey and Cyprus. Rodentia II: Cricetinae, Muridae, Spalacidae, Calomyscidae, Capromyidae, Hystricidae, Castoridae. Koper: University of Primorska, Science and Research Centre, 372 pp.

[35] Kryštufek B., Vohralík V. 2013. Taxonomic revision of the Palaearctic rodents (Rodentia). Part. 2. Sciuridae: Urocitellus, Marmota and Sciurotamias. Lynx, n. s., 44: 27-138.

[36] Yiğit N., Çolak E., Sözen M. 2016. A new species of voles, Microtus elbeyli sp. nov., from Turkey with taxonomic overview of social voles distributed in southeastern Anatolia. Turk J Zool., 40: 73-79. 